\title{
Metarrelatos, espejos y mundos posibles en Tlön, Uqbar, Orbis Tertius de Borges*
}

\author{
Metanarratives, mirrors and possible worlds in Tlön, Uqbar, \\ Orbis Tertius by Borges
}

\author{
Malva Marina Vásquez \\ Pontificia Universidad Católica de Valparaíso. Valparaíso, Chile \\ malmara@msn.com
}

\section{RESUMEN}

En Tlön, Uqbar, Orbis Tertius ${ }^{1}$ a través de la articulación en el devenir narrativo de la carga semántica de dos citas de la cultura letrada, se despliega tanto una potente deconstrucción de los metarrelatos de la metafísica moderna como una visionaria poética de la ficción fantástica. Se intenta demostrar el atentado terrorista de la audaz tesis epistemológica contenida en la cita: "la metafísica es una rama de la literatura fantástica”, la que equivale al levantamiento de la cortina de hierro ontológica por su inversión de la jerarquía de los discursos del saber moderno. Se analiza el motivo del espejo y el de la enciclopedia, entendidos como dispositivos semióticos de representación especular y escritural del mundo, respectivamente, y como ironía tanto al proyecto enciclopédico de la época moderna como a la Argentina de la Organización Nacional. Todo lo cual permite sugerir el giro epistemológico hacia un paradigma estético-narrativo en la poética postmoderna de lo fantástico de Borges.

Palabras claves: Metafísica, deconstrucción, literatura fantástica, saber moderno.

* Este artículo forma parte del Proyecto Fondecyt No 1101043 “Quiebres epistémicos y estética de lo fantástico en narrativa chilena y argentina” (2010-2012), del cual la autora es la investigadora responsable. Andrés Bobenrieth y Pablo Oyarzún (Coinvestigadores).

${ }^{1}$ Las citas a Tlön, Uqbar, Orbis Tertius al interior del artículo son de Borges 2000: 15-46. Este relato fue publicado por vez primera en la colección Ficciones 1941, en la primera parte del libro titulada El jardin de senderos que se bifurcan junto a Las ruinas circulares, entre otros. La segunda parte, se titula Artificios y consta de seis cuentos. 


\section{ABSTRACT}

In the narrative of Tlön, Uqbar, Orbis Tertius through the articulation of the semantic import of two quotes of the literate culture, it is unfolded a potent deconstruction of the meta-narratives of modern metaphysics as a visionary aesthetic of the fantastic fiction. This paper will try to reveal as a terrorist attack the audacious epistemological thesis contained in the statement: "the metaphysics is a branch of the fantastic literature", which amounts to the lifting an ontological iron curtain due for its inversion of the hierarchy of the speeches within modern knowledge. The themes of the mirror and of the encyclopedia will be analyzed, understanding both as semiotic devices of mirrorlike representation and writhing of the world, respectively, and as an irony towards the encyclopedic project of the modern age and also towards the Argentine of the National Organization. All of these allow us to suggest an epistemologic turn toward an aesthetic-narrative paradigm in Borges' post-modern view about the fantastic.

Keywords: Metaphysics, deconstruction, fantastic literature, modern knowledge.

Recibido: 03/11/2010.

Aceptado: 11/04/2011.

Torg orge Luis Borges se ha erigido en la crítica contemporánea en un ícono cultural de lo postmoderno. Muchas de las especulaciones desplegadas en su obra fantástica se anticipan en décadas a los cambios que se han venido verificando en la epistemología de estos últimos tiempos. Cambios que han posibilitado en el debate sobre lo postmoderno hablar de un giro epistemológico hacia un paradigma estético. Estas mutaciones en la cultura, las ciencias y las artes se han venido produciendo con mayor vitalidad desde los años setenta en adelante. El carácter pionero del proyecto borgeano se evidencia en el hecho de que su volumen de cuentos Ficciones, publicado el año 1941, es el libro más paradigmático y controversial, al respecto. Dentro de este volumen aparece Tlön, Uqbar, Orbis Tertius (Borges 2000: 15-46), relato hecho de guiños irónicos a la enciclopedia de la razón ilustrada de Occidente. Aquí se ostenta la cita célebre por su audaz tesis epistemológica, la que invierte la jerarquía de los discursos del saber moderno: "Los metafísicos de Tlön no buscan la verdad ni siquiera la verosimilitud: buscan el asombro. Juzgan que la metafísica es una rama de la literatura fantástica” (Borges, 2000: 29).

Para su compatriota Ernesto Sábato, esta célebre máxima se constituirá en la táctica autorial que lanza a Borges a la celebridad: "El Círculo de Viena sostuvo que la metafísica es una rama de la literatura fantástica. Y este 
aforismo que enfureció a los filósofos se convirtió en la plataforma literaria de Borges" (Sábato, 1972: 45)². De manera que en la poética borgeana, un paradigma estético que postula a la literatura fantástica como matriz de construcción de mundos, viene a subvertir el paradigma epistémico de la modernidad. Giro narrativo de la cita que también gravitará sobre los discursos históricos en el cuento, entendiéndolos como representaciones o construcciones sociales de la memoria, de la expectativa, del anhelo, lo cual permite entrever en esta ficción la propuesta de un nuevo historicismo ${ }^{3}$. Por su parte, Alfonso de Toro lo bautiza como: "El creador de los mundos virtuales digitales" porque "anticipa en los años treinta la Internet, el concepto del hipertexto y la teoría de los mundos diversos de Everett" (De Toro, 2006: 56) ${ }^{4}$. En virtud de la pionera escenificación de la muerte de los metarrelatos de la modernidad, se ha considerado a Borges como un escritor postmoderno avant la letre":

Educado en el pensamiento de Borges desde los quince años, muchas de las novedades de Derrida me han parecido algo tautológicas. No podía entender cómo tardaba tanto en llegar a las luminosas perspectivas que Borges había abierto hacía ya tantos años. La famosa "desconstrucción" me impresionaba por su rigor técnico y la infinita seducción de su espejo textual pero me era familiar: la había practicado en Borges avant la lettre. Por eso, cuando salió "La pharmacie de Platon" en los números 32 y 33 de Tel quel (1968), le eché una ojeada reverencial, verifiqué dos epígrafes de Borges que reforzaban la sección 3 (...), y pasé a otra cosa (Rodríguez Monegal, 1985: 125).

Si bien es esa práctica escritural de diálogo perverso con los metarrelatos

${ }^{2}$ Según Juan Nuño: "No es exagerado afirmar que los implacables críticos de aquel combativo Círculo de Viena se hubieran llevado muy bien con los metafísicos de Tlön. Sabido es que el principal reproche del positivismo lógico (Carnap, Ayer, para sólo citar a los cabecillas) no era que los metafísicos no dijeran la verdad, sino que pretendieran decirla cuando en realidad apenas si eran unos poetas frustrados que se ignoraban, de desigual valía y poder en sus fantásticas divagaciones" (2005: 33).

${ }^{3}$ Cambio de paradigma del discurso histórico que, de acuerdo con Jameson, se debe en gran parte a la contribución de White, quien con su texto Metahistoria. La imaginación histórica habría puesto en evidencia el carácter novelesco, es decir, ficticio de toda traducción de la sustancia de la realidad a la sustancia del discurso (Rimoldi, 2010: 51-58).

${ }^{4}$ Según De Toro, la concepción de mundos de Borges: "está estrechamente relacionada con aquella de la 'many World theory' de la teoría cuántica y, en particular, con la de Everett". Se parte del presupuesto de la existencia de muchos mundos paralelos como consecuencia de interpretaciones alternativas de procesos mecánico-cuánticos de medida"(2006: 59). 
de la metafísica occidental lo que ha consagrado a Borges en el orbe intelectual europeo, creemos que no hay que obliterar el hecho de que es la opción por lo fantástico, la estrategia "literaria" que le permite realizar la parodia de la metafísica. Ello porque la función social de lo fantástico consiste en promover una reflexión epistemológica sobre el estatus de los mundos representados (Todorov, 1978; Bessiere, 2001; Campra, 2001). Además, esta poética deconstructiva aparece ya prefigurada en su ensayo "El arte narrativo y la magia" (1932: 109-124), aparecida dos años antes de Ficciones, donde se nos ofrece una ampliada teoría de la causalidad, la que permite superar, a nivel epistemológico, la oposición binaria entre pensamiento científico y narrativo. Por ello, si en Tlön se juega a confundir las categorías de ficción literaria y discurso filosófico es porque su poética de la narración mágica o fantástica sugiere que "la magia es la coronación o pesadilla de lo causal", no su contradicción. En este sentido, la teoría de la causalidad de Borges se acerca tanto a la del pensamiento de la complejidad de humanistas postmodernos, como Daniel Bensaïd y Edgar Morin ${ }^{5}$, como a una de las versiones del constructivismo cognitivo, entre otras propuestas epistemológicas contemporáneas.

En un recorrido panorámico por la bibliografía crítica de este cuento, se advierte que la mayor parte de los estudios se ocupan con fruición de sus aspectos filosóficos o epistemológicos, de su vasta intertextualidad o diálogo con la tradición de la metafísica y la física contemporánea ${ }^{6}$. Intención no descaminada, como nos consta, ya que la modalidad de lo fantástico en Argentina tiene patente nacional, desde que Macedonio Fernández, el así llamado "Sócrates porteño", encontrara ese "estilo de lo argentino" (Gómez de la Serna cit. en Rodríguez Martín, 2010) iniciando con ello en Latinoamérica la tradición de la literatura fantástica argentina proclive a ese juego del uso periférico de la cultura filosófica occidental. "América por esa ansiedad mayor, se ve que es la que va a emprender la burla de la filosofía, gracias a un sistema de teorización veloz, remontado y genial. Macedonio ya inicia

5 "Se trata (...) de una ampliación de la noción de causalidad, admitiendo que tiene diversos tipos, incluidas las formas de causalidad psíquicas, las causalidades simbólicas, como en la teoría de las neurosis freudianas" (Bensaïd entrevistado por Spire, 2000: 149). Teoría del pensamiento complejo de Morin: "El principio dialógico permite, en suma, ligar dos nociones que lógicamente se oponen y se excluyen. El pensamiento complejo es un pensamiento que une los contrarios; el pensamiento clásico no puede unir aquello que se opone y superarlo por el principio del bucle de retroalimentación, autogenerador, que permite mostrar cómo la especie produce al individuo, pero también cómo el individuo produce a la especie, porque son los individuos los que hacen el proceso de reproducción" (Edgar Morin entrevistado por Arnauld Spire, 2000: 160).

${ }^{6}$ Algunos ejemplos de ello: Mignolo, Moreiras, De Toro, Nuño, Cédola, entre otros. 
esa burla destructora y vengativa (...)" (Gómez de la Serna cit. en Rodríguez Martín, 2010: 31-50).

\section{TLÖN: FICCIÓN DE LA ARGENTINA DE LA ORGANIZACIÓN NACIONAL}

Lyotard (1989) define lo postmoderno, surgido en el contexto de la cultura informática y massmediática de la actualidad, como síntoma de "incredulidad respecto a las metanarrativas". En el cuento, estamos en la Argentina de los años treinta, por tanto es la cultura libresca, la de la enciclopedia, la que todavía rige el imaginario social hegemónico aunque ya se profetiza sobre el advenimiento de lo postmoderno, entendido este último en el mundo narrado como la usurpación del mundo real por su doble ficticio. En él, dos sujetos letrados -Borges y Bioy Casares, personajes del cuento- se alucinarán por el sentido de dos citas librescas, iniciando una aventura del conocimiento que toma la forma de una pesquisa bibliográfica. Indagación que termina por descubrir un complot contra la realidad misma. Amelia Barili señala que "con este cuento, Borges, lector de cuentos policiales, se instala en la tradición de ese género desarrollado por británicos y estadounidenses; maneja audazmente el legado recibido y revierte las convenciones del género en clara afirmación de su identidad como escritor latinoamericano" (Barili, 1999: 188).

Si la cita del aforismo de los filósofos del Círculo de Viena nos muestra la tesis epistemológica central del cuento, a saber, que "la metafísica es una rama de la literatura fantástica”, a ella viene a sumarse la cita del pensamiento gnóstico aparecida en el volumen XXVI de la Enciclopedia en el artículo sobre Uqbar: "Para uno de esos gnósticos, el visible universo era una ilusión o (más precisamente) un sofisma. Los espejos y la paternidad son abominables (...), porque lo multiplican y lo afirman" (Borges, 2000: 17) Nos interesa demostrar que es a través de la articulación de la carga semántica de estos dos aforismos de la cultura letrada, que el relato despliega tanto una potente deconstrucción de los metarrelatos como una visionaria poética de la ficción. Veremos cómo explorar la función del dispositivo del espejo y de la enciclopedia, en tanto canales del doble fantasmático del mundo nos permitirá sustentar la tesis del giro epistemológico hacia el paradigma estético en el relato. Lo fantástico borgeano, como sabemos, es deudor tanto de la poética de lo fantástico-metafísico de Macedonio Fernández como de la poética de Poe sobre el género policial, entendidas ambas como ficciones de una "imaginación razonada", por el valor central otorgado en éstas, a 
la conjetura. En su conferencia sobre "El cuento policial", Borges nos dice que Poe "no quería que el género policial fuera realista, quería que fuera un género intelectual, un género fantástico, si ustedes quieren, pero un género fantástico de la inteligencia, no de la imaginación solamente; de ambas cosas, desde luego, pero sobre todo de la inteligencia" (Borges, 1996:193). Por otra parte, el carácter policial de la historia del descubrimiento de un tercer mundo -Uqbar: un planeta inventado- parodia tanto al proyecto enciclopédico de la época moderna como a la Argentina de la Organización Nacional. Carácter detectivesco del cuento que permite en esta segunda lectura, en clave alegórica, constatar la denuncia de las políticas del Estado en su construcción de versiones oficiales sobre el ser de la nación:

la idea clave fue la de construir un país imaginario, hacer un país en el vacío, fundado en el desierto; hay un pathos a la vez utópico y criminal en la Argentina de esos años. (...) Sarmiento expresa mejor que nadie la concepción de una escritura verdadera que sujeta la ficción a las necesidades de la política práctica: escribe desde el Estado (futuro) y en Facundo usa la ficción con toda suerte de artimañas y la define como la forma básica que tiene el enemigo de hacer la historia. Para Sarmiento la ficción condensa la poética (seductora) de la barbarie. (...) Si Facundo es el oráculo del Estado argentino, Urquiza en 1862 es el que lo descifra y lo cumple (Piglia, 1986: 129-155).

A nivel ontológico esta manera de hacer la historia promueve una inversión de los metarrelatos de la modernidad. Como es sabido, la metafísica platónica es un pensamiento binario que privilegia el mundo de lo inteligible, frente al mundo de lo sensible, siendo este último sólo su copia degradada. Es este "metarrelato", el de verdad metafísica, en tanto realidad preexistente al pensamiento, el cual se ve reducido al estatus de ficción en el cuento. Lo cual tendría su correlato en el carácter ficcional que se adjudica a la nación argentina, ya que su población está formada, mayoritariamente, por inmigrantes: "Argentina es la única cultura correspondiente a una sociedad trasplantada en América Latina, ya que cuenta con una población de origen inmigratorio establecida en una ciudad litoral, Buenos Aires, que ha comenzado a convertirse en metrópoli” (Rama, 1986: 98). Y dado que los "metarrelatos" proponen al sujeto moderno como "héroe del conocimiento" o de "la libertad" (Lyotard) ${ }^{7}$, lo cuestionado es el hecho mismo de que 
podamos acceder al conocimiento sobre el carácter de lo nacional-argentino o en su reverso, sobre el estatus ontológico del mundo. Frente al sistema de mundos metafísico, el cuento, desde su título, ya anticipa la presencia de un advenedizo - un Orbis Tertius - que termina por invertir la jerarquía del pensamiento dicotómico moderno. Se puede hablar, por ello, de una estrategia de "deconstrucción" del saber moderno en el relato".

Esta táctica deconstructiva se vale del desenmascaramiento de las paradojas que presenta el discurso metafísico y que lo inhabilitan como discurso sobre lo verdadero. Contradicciones que se hayan contenidas en el concepto metafísico de base del saber moderno, el de "representación". Si bien no podemos escapar a los condicionamientos metafísicos del lenguaje, para ilustrar cómo se da la inversión de la jerarquía de la episteme moderna contenida en la cita, proponemos sustituir el concepto de "representación" por el de "ficcionalizar" de Iser, entendido como modelo antropológico integral que ilumina la dialéctica del conocimiento. Con ello se enfatiza la lógica de la imaginación, la que nos permite convertir "posibles" imaginados en existentes. Nos hacemos eco así de la deconstrucción borgeana contenida en la cita, al descartar ésta la noción de verdad metafísica, lo cual nos permite ir de los productos, realidades preexistentes, al "proceso de construcción" de las mismas. De modo que la ventaja de esta última noción es relativizar en parte el mito esencialista de una realidad pre-dada y optar por una epistemología enmarcada en el constructivismo cognitivo ${ }^{10}$. En el cuento esta ficcionalización está connotada de manera negativa, ya que forma parte de la demagogia de los totalitarismos imperantes tanto en Europa como en América. Su contexto histórico es el de la Segunda Guerra Mundial: entre 1939 y 1945, en el cual se exacerban varias ideologías modernas como el nazismo y el comunismo ${ }^{11}$. De ahí que en el cuento se diga que: "Hace 10 años bas-

es el del sujeto cognitivo como héroe del conocimiento. El otro es el de la emancipación del sujeto histórico como héroe de la libertad. (En cap. 9 "Los relatos de legitimación del poder").

${ }^{8}$ Para Derrida: "En una oposición filosófica tradicional no encontramos una coexistencia pacífica de términos contrapuestos sino una violenta jerarquía. Uno de los términos domina al otro (axiológicamente, lógicamente, etc.), ocupa la posición dominante. Deconstruir la oposición es ante todo, en un momento dado, invertir la jerarquía" (1979: 56-57). Inversión contenida en la cita: "...la metafísica es una rama de la literatura fantástica".

${ }^{9}$ Complejo y reiterado tema el de la crisis de la noción de "representación" del saber moderno, el que nos lleva al contexto de lo postmoderno, entendida esta crisis como síntoma del "duelo del pensamiento metafísico" (Moreiras, 1999), o como "vaciamiento referencial del signo" (Jameson, 1998).

${ }^{10}$ Nos interesa reivindicar el aspecto de creatividad en la cognición, el cual aparece menoscabado en la teoría representacionalista de los mundos posibles, que los entiende como "esquemas socializados de matrices culturales".

11 "Conocida es la situación europea (Alemania, Italia, España, Rusia...). Los dirigentes ar- 
taba cualquier simetría con apariencia de orden -el materialismo dialéctico, el antisemitismo, el nazismo- para embelesar a los hombres. ¿Cómo no someterse a Tlön, a la minuciosa y vasta evidencia de un planeta ordenado" (Borges, 2000: 45).

El complot ontológico iniciado por el espejo en complicidad con la invención de una enciclopedia por parte de una secta de pensadores, científicos y artistas, continúa en el relato como una guerra ontológica en la cual vence el batallón de las copias sobre lo real. La pesquisa revela esta confabulación de sujetos letrados que, por medio de la invención y posterior institucionalización del saber libresco, promueven la ficción de la nacionalidad.

\section{PRÓTESIS ESPECULARES Y MUNDOS CONTRAFACTUALES}

La especulación sobre el espejo y la enciclopedia se intersecta en varios puntos con la de Mc Luhan -el hombre que la revista Playboy llamó "Sumo sacerdote de la Cultura Pop" y "Metafísico de los Medios". Según este autor, el surgimiento de los medios tecnológicos obliga a una reorganización de la percepción del mundo, pues todo medio es una "prótesis", es decir una extensión de nuestro cuerpo, mente o ser: "La etimología de todas las tecnologías humanas se halla en el mismo cuerpo; son, por así decirlo, artificios protéticos, mutaciones, metáforas del cuerpo o de sus partes" (Mc Luhan, 2005: 48) En el caso de los lentes o espejos, éstos son un tipo especial de prótesis del ojo, ya que ellos reflejan las cosas tal como las vemos: "Los espejos son ciertamente prótesis extensivas e intrusivas por excelencia, en el sentido de que, por ejemplo, nos permiten ver nuestro rostro y nuestros ojos, o lo que pasa a nuestras espaldas" (Eco, 1988: 20). Esta ampliación de nuestra visión revela al espejo como elemento central en la aventura del conocimiento. A esta presencia material, en tanto canal, portador de la imagen se la carga con subjetividad humana, atribuyéndosele la intención de realizar una conspiración contra el mundo. El mal cosmológico es atribuido a las imágenes especulares, ya que multiplican lo que ya es irreal e ilusorio, revelan:

un doble absoluto del campo de estímulos, el cual no puede verse impugnado por contrafactuales. (...) El espejo es una prótesis absolutamente

gentinos estarán muy vinculados al gobierno alemán hasta mediados ya los años cuarenta. Con los gobiernos militares cuasi fascistas argentinos, el país, como otros de Hispanoamérica, experimentó la organización del comunismo durante la década de los 30" (Didier, 1984: 35). 
neutra y permite captar el estímulo visual allí donde el ojo no podría alcanzar (...) La magia de los espejos consiste en que su extensividad -intrusividad no sólo nos permite mirar mejor el mundo, sino también mirarnos a nosotros mismos tal como nos ven los demás (Eco, 1988:12).

Eco afirma que las imágenes especulares son "designadores rígidos", tales como los pronombres personales o los nombres propios, puesto que presuponen necesariamente la presencia de su antecedente, el objeto referencial. Ya que Eco habla de "imágenes especulares" en tanto productos para desplegar la poética de lo fantástico acogeremos la teoría del Estadio del espejo de Jacques Lacan, por mostrar la relevancia de lo especular en la formación de lo imaginario. Teoría que sugiere que, a nivel filogenético (de memoria de la especie), la experiencia visual de nuestra imagen especular cumple un rol capital en la construcción de una matriz simbólica de subjetividad. Este estadio en tanto aventura imaginaria en la cual "el hombre experimenta que él se ve, se refleja y se concibe distinto, otro de lo que él es: es una dimensión de lo humano que estructura el conjunto de su vida fantasmática, ya que la imagen del cuerpo le permite ubicar lo que es y lo que no es del yo" (Lacan, 1990: 128). En efecto, este estadio nos muestra que la primera representación que tenemos del mundo es la de nuestro cuerpo y entorno reflejado en el espejo, conformándose éste en el primer medio tecnológico de acceso al conocimiento, a la vez que en el dispositivo fundador de lo fantástico: del motivo del doble y de los mundos comunicantes.

El espejo sería así el primer medio de traducción de lo real, en esa escalada de traducciones que van en orden de sucesión del pensamiento al lenguaje hablado y de éste, a la escritura.

De acuerdo a la clasificación de mundos del sentido común, el espejo funciona como mundo enmarcado dentro de lo que llamamos el mundo real. Pero es interesante destacar que el espejo, tal como las fotografías, novelas, películas, posee una existencia objetiva, -muestra imágenes exterioresen oposición a otros mundos enmarcados que se producen en la interioridad de un sujeto: las imaginaciones, los sueños (Hahn, 1978). Se revela así como dispositivo instaurador de la paradoja a nivel perceptivo, delatando la estructuración fantasmática de lo real. Este primer boceto de identificación imaginaria será un contorno que contendrá todas las imágenes constitutivas del yo imaginario. De este modo, el reconocimiento de su imagen en el espejo sitúa "la instancia del yo, aun antes de su determinación social, en una línea de ficción” (Lacan, 1989: 87). Eco señala que "nos cuestionamos si la semiosis funda la percepción o la percepción funda la semiosis (...) Las 
reflexiones de Lacan sobre la etapa del espejo nos sugieren que percepción (o, al menos, percepción del propio cuerpo como unidad no fragmentada) y experiencia especular van a la par. El espejo es un fenómeno-umbral que marca los límites entre imaginario y simbólico (semiósico)" (Lacan, 1989: 19). Un atentado contra la razón humana es la experiencia ofrecida por el espejo: "La "razón" se declara contra el espejo que no ofrece al mundo sino una imagen del mundo, una materia desmaterializada, en una palabra, una contradicción frente a la ley de no contradicción" (Todorov, 1978: 146). La imagen especular; "umbral del mundo visible" actúa como puente que funda al mismo tiempo que transgrede la dicotomía del sentido común: mundo exterior versus mundo interior. Así, en Tlön el espejo actuaría como el primer dispositivo de "deconstrucción" al poner en marcha un desmontaje crítico de las oposiciones jerárquicas de los sistemas teóricos.

\section{POÉTICAS DE LA FICCIÓN Y MUNDOS POSIBLES}

Postular una poética de la ficción fantástica como conjunto que subsume los mundos posibles es nuestro intento en este apartado. Ello dado la apertura de la modalidad narrativa de lo fantástico a lo impensado y además, por su crítica al universo de la representación. De ahí que nos parezca desacertada la opinión de que "con el postulado de mundos que existen paralelamente, Borges supera la literatura fantástica”. (...) "Mi teoría de 1998 en la que planteaba que los famosos relatos fantásticos de Borges son más bien antifantásticos" (Alfonso de Toro, 2006: 60). Eco nos recuerda que "el contrafactual con que juega la literatura fantástica es de este tipo: ¿Qué sucedería, si el mundo real no fuera semejante a sí mismo, es decir, si su estructura fuera distinta?" 12 (Eco, 1988: 221). Nuestra propuesta reivindica una poética de la ficción fantástica entendida como quiebre epistémico:

Nacido en medio del universo mimético y sirviéndose de él para inscribir sus pasos, tiende a subvertirlo, a cuestionar sus certezas. El texto fantástico subvierte los mecanismos y los presupuestos del texto mimético, con el fin de dejar paso a lo impensable, que intenta representar de una manera ambigua (...) Así pues se erige como el lugar y el medio para una crítica del universo de la representación, instaurando por eso mismo un vértigo

12 "Un contrafáctico es definido como un enunciado condicional en el cual interviene la noción de posibilidad, expresada gramaticalmente por la introducción del subjuntivo” (Eco, 1988: 222). 
de la razón desconcertada. Pero no en el marco de un discurso subversivo, sino mediante la puesta en práctica de la subversión de todo discurso fiable y por la instalación en los "márgenes" de lo pensable y de lo representable, de una efectiva alteridad (Bozetto, 2001: 224).

Las ventajas teóricas de "lo fantástico" para realizar la deconstrucción de la metafísica vienen dadas por el carácter esencialmente histórico de esta modalidad narrativa (Todorov, 1978; Bessiere, 2001). Al ser un género que cuestiona su propia episteme, tiene la ventaja de no presentar un compromiso ontológico previo en su estructuración de mundos. De ahí su función social de promover una reflexión epistemológica sobre los diferentes modelos o sistemas de realidad en su devenir histórico. Por otro lado, dado que la configuración de mundos contrafactuales o alternativos es central en lo fantástico, éste puede funcionar como conjunto que abarca todo tipo de ficciones. Para comprobar este último aserto, nos preguntaremos ¡cuál es la naturaleza de los entes de ficción? Para responder a esta cuestión, filósofos y estudiosos de la literatura, en un acercamiento interdisciplinario, optaron por el enfoque ontológico, por la naturaleza del hábitat que acoge a los entes de ficción, para el cual propusieron la noción de "mundo posible"13. Por lo cual la pregunta apropiada ya no será si existen o no existen los entes de ficción sino en qué tipo de mundo posible tienen su existencia.

Para iluminar la relación entre la noción de mundo posible y la modalidad narrativa de lo fantástico, es necesario partir por la Poética donde Aristóteles hace la diferencia entre historiografía y poesía: "No es asunto del poeta decir lo que pasó, sino el tipo de cosas que pasarían, lo que es posible según la posibilidad y la necesidad". Se explica, aquí, la noción de ficción literaria, por medio del concepto de "mímesis": "la representación verosímil de la realidad". Pero, la modalidad de la posibilidad es mucho más amplia que la de "mímesis": "Decimos que p es posible, si hay al menos una situación imaginable en la que $\mathrm{p}$ es verdadera. La semántica modal ha introducido una noción técnica para tal situación imaginable, la noción de $M U N D O$

\footnotetext{
${ }^{13}$ Noción atribuida a Leibniz, quien se representaba a Dios cotejando combinaciones lógicas diferentes de individuos y eligiendo este mundo como el conjunto más vastamente compatible. Esta noción es recuperada en el marco de la lógica modal; la que estudia las "actitudes proposicionales” por Saúl Kripke en 1959, y serán los cultivadores de esta disciplina quienes contribuirán a su desarrollo. Los intentos iniciales de formular aproximaciones de mundos posibles a las ficciones literarias se produjeron en los años 70 (Van Dijk; Pavel; Eco; Dolezel y Kanyó). En el campo de la teoría literaria merece destacarse la contribución de K. Hamburger, P. Ricoeur, L. Dolezel, Th. Pavel, F. Martínez Bonati, S.J. Schmidt, etc. y los recientes trabajos de Cuesta Abad y de T. Albaladejo Mayordomo. Veáse: Dolezel, 1997a.
} 
POSIBLE" (Van Dijk, 1988: 69). Una gran ventaja de la noción de "mundo posible" es su carácter de constructo:

Obsérvese que la noción de mundo posible no debe identificarse con nuestras ideas intuitivas de (nuestro) "mundo", "realidad", etc., sino como un constructo abstracto de teoría semántica (teoría de modelos). Un mundo posible, como el término posible sugiere, es también un estado de cosas que no es verdadero, pero que podría haber sido verdadero. Esta posibilidad puede ser de varios tipos: podemos imaginar una situación donde los hechos son diferentes de los hechos reales o verdaderos, pero compatibles con los postulados (leyes, principios, etc.) del mundo real (Van Dijk, 1988: 61).

Pero el aporte fundamental de esta teoría dada su ampliación de la cartografía de lo posible es el de incluir los mundos antimiméticos: "Por otra parte, podemos imaginar mundos con leyes de la naturaleza en parte o enteramente diferentes, es decir, mundos que son progresivamente DISTINTOS de nuestro 'propio' mundo, o más bien del conjunto de los mundos que podrían haber sido el mundo real, es decir aquellos mundos que satisfacen la misma serie de postulados básicos" (Van Dijk, 1988: 63). De modo que la noción de "mundo posible" se acerca a una poética integral de la ficción. Desde la poética suiza, Breitinger es quien explica la tesis básica de una poética no mimética de mundos ficcionales, al extender el concepto de naturaleza (realidad) e identificarlo con el universo leibniziano: el universo de los mundos existentes. De este modo, la naturaleza: "objeto de la imitación poética, no sólo está constituida por el mundo real sino también por un número infinito de mundos posibles cuyos constituyentes y estructuras podrían ser substancialmente distintos de la realidad" (Breitinger cit. por Dolezel, 1997b: 69). Y el acto mediante el cual el poeta convierte posibles en existentes ficcionales se realizaría mediante el ficcionalizar:

Todo poema bien inventado tiene que ser visto, por tanto, como una historia de otro mundo posible. A este respecto, el poeta merece el nombre de poietes, 'creador', porque a través de su arte es capaz no sólo de otorgar formas visibles a cosas invisibles sino de crear cosas que no son para los sentidos, es decir, de transformarlas desde el estado de posibilidad al estado de realidad y, de este modo, darles la apariencia y el nombre de realidad (Dolezel, 1997b: 69). 
De modo que a nivel epistemológico, la gran contribución de la teoría de los mundos posibles al análisis literario es la propuesta de una semántica constructiva. Según Auerbach, la idea de la mímesis ${ }^{14}$, ha dominado el pensamiento estético occidental desde Aristóteles, quien en la Poética privilegia la verosimilitud como categoría para valorar las obras literarias. De acuerdo a la primera acuñación del concepto de "mundo posible" por parte de Leibniz, en tanto categoría filosófica de un realismo metafísico, los mundos se "descubren" y, en tal caso, sólo cabe como tarea el describirlos. Pero, desde el constructivismo cognitivo: "Los mundos posibles no se descubren en depósitos lejanos, invisibles o trascendentes, sino que son construidos por mentes y manos humanas" (Dolezel, 1997a: 88).

\section{MUNDOS POSIBLES: JUEGOS DE CIENCIA FICCIÓN}

El atentado terrorista que pone en práctica la cita: "los tlönianos juzgan que la metafísica es una rama de la literatura fantástica", equivale al levantamiento de la cortina de hierro ontológica que algunos filósofos del lenguaje habían férreamente construido para que los seres de la ficción no invadieran el territorio de lo real. Dado que: “(...) los metafísicos de Tlön no buscan la verdad ni siquiera la verosimilitud: buscan el asombro" (Borges, 2000: 29) metafísica y literatura fantástica se homologan en esta concepción de mundo. Asombro que hacemos asimilable a la experiencia de lo fantástico como experiencia de extrañamiento, que transmuta la percepción habitual de la realidad en lo "siniestro" (Freud, 1988). El discurso metafísico pertenece al género de los discursos filosóficos y su estatus como metarrelato en la modernidad se da precisamente como relato del "saber de la verdad". Por el contrario, el género literario debe su estatus a la diferenciación entre lo serio y lo no serio, adjudicándosele así el calificativo de "lo no verdadero". La fórmula es la siguiente: "Los textos literarios 'parecen denotar' o la literatura 'no hace oraciones con valor de verdad', compartiendo ese estatus epistémico 'con tipos de discurso como los ejemplos, las explicaciones, las preguntas, las órdenes, los sueños, los saludos, los deseos, los pensamientos, las opiniones y otros'" (Schmidt en Dolezel, 1997a: 158).

Este encarnizado juicio contra la ficción cuenta con una larga tradición en la filosofía occidental. Como uno de sus hitos fundamentales podría-

\footnotetext{
${ }^{14}$ Auerbach, mímesis en su sentido más lato, de que las ficciones se derivan de la realidad, son imitaciones/representaciones de entidades realmente existentes (Dolezel, 1997b: 71-72).
} 
mos señalar la censura platónica de la poesía, al calificarla el filósofo como la mentira del verbo en La República. Actualmente, este debate ha contado con ilustres representantes de la filosofía analítica como Frege, Quine, Strawson, Russell, entre otros y, especialmente, aquellos autores que se inscriben en el ámbito de la pragmática filosófica con la teoría de los actos de habla: Austin y Searle, principalmente. Para un teórico de la ficción como Thomas Pavel:

El rasgo menos atractivo de estas tentativas de acabar con la ficción es su perspectiva normativista. El menosprecio hacia los límites territoriales representa para estos autores una seria transgresión filosófica. Russell y Kripke diseñan sus mecanismos lógicos a fin de impedir que los seres ficticios se introduzcan en los dominios de la realidad, o de la realidad y la posibilidad filosóficamente aceptable consideradas conjuntamente. De forma similar, las observaciones de Searle trazan una línea excesivamente clara entre las afirmaciones pragmáticamente serias y los engaños de la ficción (Pavel en Dolezel, 1997a: 173).

Sin embargo, las ficciones literarias a diferencia de otras ficciones, como la mentira "muestran su ficcionalidad" (Iser, 1997), al mostrar la "emergencia de la subjetividad" de los personajes. En el caso de lo fantástico, esto nos lleva a reivindicar el ficcionalizar como modelo del pensar que se abre a lo impensado, esto es, a la producción de un tipo de subjetividad que no es una mera reproducción de las significaciones dominantes, de lo dado. Señala Iser que si las "fronteras del conocimiento activan la ficcionalización, quizá pueda observarse un principio de economía: no es necesario inventar lo que se puede conocer; y por eso las ficciones siempre contribuyen a salvar lo impenetrable" (Iser, 1997: 62). Es un hecho que frente a lo desconocido, todos ponemos en marcha la narrativa de la conjetura, que construye primero un mundo posible imaginario: "Debemos tener en cuenta que la realidad que se ha visto sobrepasada no se deja atrás; permanece presente, y con ello dota a la ficción de una dualidad que puede ser explotada con propósitos distintos" (Iser, 1997: 47). Un ejemplo paradigmático de ficción, para Iser, la cual siempre contiene al menos dos mundos, es la mentira, puesto que ésta incorpora la verdad y la intención por la cual ésta debe ser encubierta. De ahí que sostenga que el ficcionalizar siempre "provoca la simultaneidad de lo que es mutuamente excluyente" (1997: 64). Podríamos hablar, en un caso, de cognición, en la cual los fenómenos se interpretan de acuerdo a la activa- 
ción de nuestro conocimiento de mundo. Y de "metacognición"15, cuando la ampliación del horizonte cognitivo resulta de la interacción con lo desconocido para el cual se requiere del tipo de razonamiento de la "metaabducción" (abducción creativa). Según Peirce, el razonamiento por metaabducción es típico de todos los descubrimientos "revolucionarios", puesto que, tal como lo señalara Kuhn, éstos cambian un paradigma científico establecido. Tlön es la invención de un planeta desconocido por parte de una sociedad secreta de astrónomos, de biólogos, de ingenieros, de metafísicos, de poetas, con lo que se sugiere que la dinámica de la invención es la misma tanto en el arte, la ética, como en la ciencia. El acto de ficcionalizar está presente así en todos los ámbitos del quehacer humano, ya sea a nivel mental como anticipación de la acción en nuestra vida cotidiana, lo cual nos permite actualizar nuestras propias posibilidades futuras o bajo la forma de hipótesis en la ciencia.

\section{EL HOMBRE: JUGADOR DE ROLES}

El hombre: "es un ser generalmente inseparable de un rol social pero no definido por un rol concreto. (...). Unicamente a través del otro de nuestro propio ser tenemos un ser propio. Con esta estructura del doppelganger que vincula al que representa una figura con la figura representada creemos haber encontrado una constante (...)" (Iser, 1997: 54-55). De manera que el ficcionalizar actualiza ese proceso creativo, provisorio, de las definiciones "porque no hay definición histórica, natural o racional que nos permita establecer dichas definiciones una vez por todas. 'La persona es eso que no es lo que es y que es lo que no es', como ya dijo Hegel” (Iser, 1997: 53). Así, si frente a lo desconocido, en cualquiera de nuestras actividades, ponemos en marcha la narrativa de la conjetura, la diferencia específica entre unas ficciones y otras estaría dada por las reglas que están en la base de su producción como juegos de lenguaje, y que determinan su estatus ontológico como convención socializada. Según Eco y Sabeok: "Toda operación científica (pero no estoy pensando sólo en las ciencias físicas, sino también en las hipótesis del psicoanalista, del detective, del filólogo, del historiador) se origina en un

15 Según Bruner “(...) la función de la metacognición en tanto intervención reflexiva en el (proceso de conocimiento)” juega un rol capital en la creación de cultura, ya que: "La reflexión y el distanciamiento son aspectos fundamentales para lograr un sentido de la serie de posibles actitudes, un paso metacognitivo de enorme importancia” (1994: 137). En relación al fenómeno de la metaabducción, véase: Umberto Eco y Thomás A. Sabeok (1989: 265-294). Los tres tipos de abducción son: Hipótesis o abducción hipercodificada, abducción hipocodificada, abducción creativa. A esa última corresponde la metaabducción. 
profundo juego de ciencia-ficción, (...) en una forma particularmente aventurada de conjetura científica" (1989: 191). Pero la ciencia como juego de lenguaje: "parte de un resultado factual que debe explicar mediante la elaboración de la ley de un mundo estructuralmente posible" (Eco, 1988: 190).

El rol del científico, de este modo, es actualizar lo posible verificable, lo que le permite producir saber y divulgarlo. Por su parte, la ciencia ficción "imagina un resultado contrafactual", pero "no está obligada a imaginar una ley inédita que lo explique: puede intentar explicar el resultado factual con una ley real (...)" (Eco, 1988: 191). Las ficciones de la ciencia son así "ficciones de acuerdo", ya que las hipótesis deben ser verificables. La conjetura borgeana viene a concordar con la hipótesis siguiente: "Hay algo artístico en el descubrimiento científico (...) (si supusiéramos que éste (...) no identifica un orden dado del cosmos, sino que somete nuestra imagen del cosmos a su orden) y hay algo científico, en el sentido de algo abductivo, en lo que el vulgo llama la fantasía del artista" (Eco, 1988: 191). Para la teoría constructivista de mundos lo real es un "constructo epistémico" (Foucault) y, por ende, un saber provisorio. Así nuestro "mundo real es sólo un elemento de un conjunto de mundos posibles" (Van Dijk, 1988: 63). Esto también lo saben los sabios de Tlön, para quienes: "Un sistema no es otra cosa que la subordinación de todos los aspectos del universo a uno cualquiera de ellos". Borges señala además que "notoriamente no hay clasificación del universo que no sea arbitraria y conjetural. La razón es muy simple: no sabemos qué cosa sea el universo (...) Cabe ir más lejos; cabe sospechar que no hay universo en el sentido orgánico, unificador, que tiene esa ambiciosa palabra" (Borges, 2000: 12). El problema estaría en la idea misma de mundo; "el inconcebible universo", ya que al situarse más allá de toda posible experiencia sensible no puede ser conocido.

Acerca de la cosmovisión de los tlönianos: "Su idealismo es así, absoluto, pues como observa Borges, para los de Tlön, la res cogitans 'pienso, luego existo' es un sinónimo perfecto del cosmos" (Nuño, 2005: 31). Se parodia así el itinerario del pensar moderno que se inicia con el cogito, ergo sum de Descartes, que privilegia a la razón especulativa como propiedad distintiva de lo humano. Si bien ésta se abre a la aventura de la imaginación termina por descubrir que no puede salir del laberinto de sus representaciones. La filosofía entendida así como juego dialéctico, conduce a la creación infinita de mundos en Tlön. Creemos que el autor implícito del relato se vale de la paradoja no para promulgar un nihilismo pasivo que niegue todo sentido, sino por el contrario, para escenificar la creación de mundos como juego dialéctico, creador de la abundancia de sentidos. Su poética parecería ser fiel al 
siguiente imperativo estético-filosófico: “(...) se trata de volver a tomar conciencia explícita de la multiplicidad abierta de lo real” (Savater, 1992: 49).

El motivo de los "mundos comunicantes" adviene en la tercera parte de la narración; la llamada Postdata de 1947. Borges-escritor registra en ella que han transcurrido 7 años después de la aparición del relato anterior y que éste constituye un artículo que apareció en la Antología de la literatura fantástica, 1940. Nueva vuelta de tuerca por medio de la cual se inscribe al relato anterior en la ficción, y de hecho el título de ésta coincide con la primera, de muchas antologías que Borges realizara en colaboración con Bioy Casares. Y por fin asistimos a la elucidación del misterio de Tlön que se basa en el descubrimiento fechado de una carta. Ésta entrega los antecedentes históricos de cómo se fue formando una sociedad secreta que tuvo entre sus afiliados a George Berkeley. La perseguida fraternidad resurge en América, donde se propone la invención de un planeta, ya que "en América es absurdo inventar un país". Resultado de lo cual se cuenta con la Primera (Borges, 2000: 40) Enciclopedia de Tlön. Si bien antes se nos habló del mundo posible tlöniano, el tercer mundo, también se nos advirtió que "siglos y siglos de idealismo no han dejado de influir en la realidad". "Aquí doy término a la parte personal de mi narración. Lo demás está en la memoria (cuando no en la esperanza o en el temor) de todos mis lectores" (43). Se sugiere aquí, que el mundo no posee una naturaleza intrínseca, sino que se da por la participación activa, contingente, de la subjetividad humana en la construcción futura de realidad. Así frente al mito esencialista de lo dado de la metafísica platónica, se alza una epistemología participativa ${ }^{16}$ (Tarnas, 1991), que daría cuenta del carácter interpretativo y constructivo del conocimiento humano.

\section{LO OTRO: LO SUBLIME GNÓSTICO}

En una de sus intervenciones públicas, Borges afirma: "Es la idea de un libro que transforma la realidad y transforma el pasado. Me di cuenta de que eso había ocurrido siempre. Porque al fin de todo, nosotros somos obra de la Biblia y los Diálogos platónicos" (Carrizo, 1982: 222). Si bien Borges en la

16 "La mente occidental ha peleado siglos con pasión (...) forjó el yo autónomo individual, la posición epistemológica cartesiano-kantiana, que ha sido el paradigma dominante del pensamiento moderno. Pero ahora vuelve a reunirse con el fundamento de su ser". Y apelando a una perspectiva epistemológica más refinada, añade: "Los principios subjetivos que determinan nuestro conocimiento del mundo no pertenecen al sujeto humano aislado, son en realidad expresión del ser propio del mundo. La realidad no es ni fenoménica ni objetiva, ni interior ni exterior, es el propio ser del pensar humano. El a priori es nuestra pertenencia al cosmos" (Tarnas en Prólogo a Ferrer, 2008: 13-19). 
cita reconoce los dos textos fundadores de la episteme moderna de la cultura occidental, ¿por qué a la hora de concebir su ficción se queda sólo con el platonismo para representar el mundo tloniano? Creemos que la exclusión del relato bíblico tiene su explicación en el hecho de que los inventores de Tlön pertenecen al pensamiento gnóstico ${ }^{17}$. Los gnósticos, según Grant, animados por una voluntad de interpretación revisionista no sólo de la Biblia sino también de Homero, van más allá del pensamiento apocalíptico y abandonan el judaísmo y el cristianismo al negar la verdadera divinidad del Dios creador. Y ¿qué conoce, entonces, un gnóstico?, el adepto gnóstico Monoimus nos informa al respecto: "Abandona la búsqueda de Dios y la creación (...) búscala tomándote a ti mismo como punto de partida. Aprende quién es el que dentro tuyo hace que todo se vuelva propio y dice: mi dios, mi mente, mi pensamiento, mi alma, mi cuerpo. (...) Si buscas estas cuestiones las encontrarás en ti mismo" (Bloom, 2000: 275-276).

Las representaciones de la propia subjetividad son así el único objeto posible de conocimiento para el pensamiento gnóstico, al igual que para los tlonianos ${ }^{18}$, y en esta autoconciencia buscan su libertad. Como el platonismo, la teología cristiana también está organizada alrededor de una oposición jerárquica entre la noción de un ámbito divino trascendente (la verdad) y un mundo corpóreo (la apariencia); otro metarrelato. Por el contrario, lo cautivante es que estos planos de realidad no se mezclen en el mundo tloniano: "Inútil responder que la realidad también está ordenada. Quizás lo esté, pero de acuerdo a leyes divinas -traduzco: a leyes inhumanas- que no acabamos nunca de percibir. Tlön será un laberinto, pero es un laberinto urdido por hombres, un laberinto destinado a que lo descifren los hombres" (Borges, 2000: 45). La presencia del mal ontológico en el mundo ${ }^{19}$, prefigurada en la presencia del espejo, se revela así inspirada en el pensamiento gnóstico: "En el aspecto teológico esta doctrina señala (...) que el verdadero dios, estrictamente, transmundano, no es revelado ni indicado por el mun-

${ }^{17}$ Además, habría que agregar también el carácter hermético y esotérico del cuento. Para ello, véase Didier, 1984: 25-39. Para las conexiones del relato con la comunidad de los Rosa-Cruz, veáse Navarro, 1997.

${ }^{18}$ Según Scarfó: “(...) el nombre dado a una enciclopedia escrita en uno de los lenguajes de Tlön refiere a una visión en el gnosticismo tardío de que existía un Orbis Tertius entre el Orbis Primus espiritual (imposible) y el inferior o causal (Posible)" (2000: 78).

19 "De la misma manera, en su aspecto cosmológico afirma que el mundo no es la creación de Dios sino de un principio inferior cuya ley ejecuta; y en el aspecto antropológico, que el yo interno del hombre, el pneuma ("espíritu" en tanto distinto del "alma"= psiquis), no es parte del mundo, de la creación y la naturaleza, sino que es tan incognoscible y trascendente para todas las categorías mundanas como su contraparte transmundana, el desconocido Dios exterior" (Bloom, 2000: 275-276). 
do y es, por lo tanto, lo Desconocido, lo completamente Otro, incognoscible en términos de cualquier analogía mundana" (Bloom, 2000: 275). Y, en efecto, en Tlön la catástrofe de usurpación de un mundo por el otro aparece incubada en el corazón mismo de lo real: "Casi inmediatamente, la realidad cedió en más de un punto. Lo cierto es que anhelaba ceder (...)" (Borges, 2000: 45). Confirmamos así, que el complot contra la realidad viene habilitado por la realidad misma. Lo cual apunta a una noción de lo real que supera el dualismo entre el sujeto cognoscente y el objeto cognoscido y que, por lo tanto, supera también tanto el "mito del marco" como el "mito de lo dado" o la realidad:

Todo conocimiento humano del mundo está determinado, en cierto sentido, por principios subjetivos; pero en lugar de considerar que estos principios pertenecen al sujeto humano separado y, por tanto, carecen de fundamento en el mundo exterior, independiente del conocimiento humano, la concepción participativa sostiene que tales principios subjetivos son en realidad expresión del ser propio del mundo, y que la mente humana, en último término, es el órgano del propio proceso de autorrevelación del mundo (Tarnas, 1991: 229).

La presencia de un "fundamento en el mundo exterior" que permite avalar esta epistemología participativa en Tlön, son el espejo y la enciclopedia. De modo que esto descarta el problema de la mediación, entendido según moldes cartesiano-kantianos (los llamados principios mediadores; el mito del marco), para situar la mediación en lo real mismo; el espejo como mediación material a través del cual la realidad se automanifiesta en el locus de lo humano. De ahí que Tlön al promover un movimiento narrativo de metatopía y metacronía se acerca a la ciencia ficción, en la cual el mundo posible representa una fase futura del mundo real presente: "justificada siempre por rasgones y desmalladuras del tejido espacio-temporal (...)" (Eco, 1988: 188). Estas desmalladuras son producidas por las imágenes especulares y la enciclopedia, lo que enmarca el relato en el cruce entre lo fantástico y la ciencia ficción.

\section{DE LA CIUDAD LETRADA A LA ALDEA GLOBAL}

En esta era que comenzó con la reproducción técnica del mundo y desemboca en la sociedad informática de nuestra contemporaneidad, somos testi- 
gos del momento apocalíptico de la ciudad letrada, ya que las copias ahora vehiculizadas por los mass media -por las pantallas "para-especulares" (Eco, 1988) - han consumado el proceso de usurpación de lo real. La ironía final del narrador se evidencia al decir que está realizando una traducción que no dará a la publicación, para no participar en este complot de las copias que devoran lo real. Lo cual, en el contexto de la cultura latinoamericana nos lleva a la reflexión sobre las contradicciones en que se ha fundado el proyecto de nación moderna por parte de los sujetos letrados. Borges desplaza, así el tema "bien argentino", al decir de Piglia: el complot, la conspiración en tanto "relato paranoico" que revela como funciona el poder estatal en Argentina, al plano de una especulación cosmológica.

El giro epistemológico hacia un paradigma estético se da como proceso paulatino de usurpación de lo real por lo imaginario-virtual, proceso que en la cultura de la pantalla tiene su momento climático en la llamada "neotelevisión", la cual instaura una espacialidad inédita muy diferente a la de la ciudad letrada. Si esta última estaba configurada como espacio geográfico, objetivo, la urbe actual se configura "como uno de los espacios públicos que moldean nuestra vida de sujetos del ver y hacen de nosotros sujetos arrancados de nuestro lugar propio, proyectados en un lugar tópico -de todos (...)-, un no mans' land moderno en el que nos transporta la ilusión (la ilusión de ver y de ser) que nos proyecta en otros mundos, mundos posibles, mundos de ficción, de lo virtual, del poder-ser" (Imbert, 2003: 55). Pasamos, así, abruptamente de la alegoría y parodia en Tlön de la construcción ficcional del concepto de nación en Argentina por parte de los sujetos letrados, a la consumación del mundo tlöniano, ficcionalizado ahora por la actual cultura massmediatizada de la globalización.

Hoy, asistimos a un "desplazamiento y parcial conversión de la ciudad letrada en la ciudad corporativizada, en la ciudad enchufada a los circuitos de circulación de información global, o en la ciudad tele-espectadora" (Remedi, 1996: 119). Surge el desafío de reterritorializar el análisis cultural que contemple una reconfiguración del campo de producción cultural global, ya que la desarticulación espacial de la ciudad letrada, a la cual Rama le asignaba un rol crucial en "el ordenamiento espacial en la actividad social, en las relaciones humanas, en la administración de la producción de sentidos y sensibilidades (...)" (Remedi, 1996: 122) da paso a un mundo ontológicamente híbrido donde las categorías realidad versus ficción empiezan a compartir y disputar un mismo estatus de existencia. Lo cual viene a desembocar en un cuestionamiento epistemológico de la noción misma de "representación", de "mundo" y de "identidad". Borges se adelanta así en 
décadas (1941) con su profética sentencia "el mundo será Tlön", a la etapa de consumación de la aventura del conocimiento del sujeto moderno.

\section{REFERENCIAS}

Barili, Amelia. 1999. Jorge Luis Borges y Alfonso Reyes. La cuestión de la identidad del escritor latinoamericano. México: F.C.E.

Bessiere, Irene. 2001. "El relato fantástico: forma mixta de caso y adivinanza”. En Teorías de lo fantástico. Madrid: Arco/Libros, S.L.

Bloom, Harold. 2000. Poesía y Represión. Buenos Aires: Adriana Hidalgo Editora.

Borges, Jorge Luis. 1932. "El arte narrativo y la magia”. En Discusión. Buenos Aires: Gleizer, pp. 109-124.

.1996. "El cuento policial”. Obras Completas IV. Barcelona: Emecé, pp. 189-197.

. 2000. Narraciones. Buenos Aires: Emecé Editores, pp. 15-46. . 2007. "Los espejos abominables". En Historia Universal de la Infamia. Extraído de: Obras Completas. (1996) Tomo 1. Buenos Aires: Emecé.

Bozzetto, Roger. 2001. ¿Un discurso de lo fantástico? En Teorías de lo fantástico. Madrid: Arco/Libros, S.L.

Bruner, Jerome. 1994. Realidad mental y mundos posibles. Barcelona: Editorial Gedisa.

Campra, Rosalba. 2001. "Lo fantástico: una isotopía de la transgresión”. En Teorías de lo fantástico. Madrid: Arco/Libros S.L., pp. 153-191.

Carrizo, Antonio. 1982. Borges, El memorioso, Conversaciones de Borges con Antonio Carrizo. México: F. C. E.

Cédola, E. 1993. Borges o la Coincidencia de los Opuestos. 1993. Buenos Aires: Eudeba.

Derrida, Jacques. 1979. Posiciones. Valencia: Pretextos.

De Toro, Alfonso. 1997. "Prólogo" a Ferrer, Jorge. En La espiritualidad creativa. La pasión del pensamiento occidental. Barcelona: Editorial Prensa Ibérica.

. 2006. "Borges virtual. El creador de los medios virtuales digitales", en Revista Aisthesis 39, pp. 49-71.

Didier, Jean. 1984. "The Esotheric Tradition in Borges: Tlon, Uqbar, Orbis Tertius". Studies in Short Fiction.

Dolezel, Lubomir. 1997a. Teorías de la ficción literaria. Madrid: Arco/ Libros.S.L. 
1997 b. Historia de la Poética. Madrid: Editorial Síntesis.

Eco, Umberto. 1988. De los espejos y otros ensayos. Barcelona: Editorial Lumen.

Eco, U. y Sabeok, T. A. 1989. El signo de los Tres. Dupin, Holmes, Peirce. Barcelona: Editorial Lumen.

Ferrer, Jorge. 2008. La espiritualidad creativa. Barcelona: Editorial Kairós.

Freud, Sigmund. 1988. "Lo ominoso". Volumen XVII. Obras Completas. Buenos Aires: Amorrortu Editores.

Foucault, Michael. 1970. La arqueología del saber. México: Siglo XXI Editores.

Hahn, Oscar. 1978. La literatura fantástica en el Cuento hispanoamericano. México: Premia Editora.

Imbert, Gerard. 2003. El zoo visual. Barcelona: Editorial Gedisa.

Iser, Wolfang. 1997. "La ficcionalización: Dimensión Antropológica de las ficciones literarias", en Teorías de la ficción literaria. Madrid: Arco/ Libros.S.L.

Jameson, Frederic. 1998. El giro cultural. Escritos seleccionados sobre posmodernismo. 1983-1988. Buenos Aires: Manantial.

Lacan, Jacques. 1989. Escritos II. México: Siglo XXI. . 1990. "La tópica de lo imaginario", en El seminario. Buenos Aires: Ediciones Paidós.

Lyotard, François. 1989. La condición postmoderna. Editorial Cátedra: Madrid.

Mac Luhan, Marshall y B.R. Powers. 2005. La Aldea Global. Barcelona: Editorial Gedisa.

Mignolo, Walter. 1977. “Emergencia, Espacio, 'Mundos posibles': Las propuestas Epistemológicas de Jorge L. Borges”, en Revista Iberoamericana 100-101, pp. 357-379.

Moreiras, Alberto. 1999. Tercer Espacio: Literatura y duelo en América Latina. Santiago: LOM Ediciones.

Navarro, Juan. 1997. "La alquimia del verbo: Tlön, Uqbar, Orbis Tertius de J.L. Borges y la Sociedad de la Rosa Cruz", en Hispanófila 120, pp. 67-80.

Nuño, Juan. 2005. La filosofía de Borges. Barcelona: Reverso Ediciones.

Piglia, Ricardo. 1986. Critica y Ficción. Barcelona: Anagrama.

Rama, Angel. 1986. La novela en América Latina. Panoramas 1920-1980. Bogotá: Instituto Colombiano de Cultura. 
Remedi, Gustavo. 1996. "La ciudad letrada: Angel Rama y la espacialización del análisis cultural”. En: Angel Rama. Estudios críticos. Mabel Moraña, Editor, pp. 97-122.

Rimoldi , Lucas. 2010. "Borges y la predicción de un nuevo historicismo", en Taller de Letras 46, pp. 51-58.

Rodríguez Martín, M. 2010. "Macedonio Fernández: entre la fuga y el canon”, en Taller de Letras 46, pp. 31-50.

Rodríguez Monegal, E. 1985. “Borges \& Derrida: Boticarios”. Maldoror 21. "Jacques Derrida: Primeras (P) Referencias", Montevideo.

Sábato, Ernesto. 1972. Tres aproximaciones a la literatura de nuestro tiempo. Santiago: Editorial Universitaria.

Savater, Fernando. 1992. Invitación a la ética. Madrid: Cátedra.

Scarfó, Daniel. 2000. "Borges y las Literaturas Imposibles". En: Jorge Luis Borges: Intervenciones sobre Pensamiento y Literatura. Compiladores: Rowe, Canaparo, Louis. Buenos Aires: Paidós.

Spire, Arnauld. 2000. El pensamiento de Prigogine. Santiago: Editorial Andrés Bello.

Tarnas, Richard. 1991. La pasión del pensamiento occidental. Colección Memoria Mundi. Cartoné. Vilaür: Ediciones Atalanta.

Todorov, Tzvetan. 1978. Introducción a la literatura fantástica. Buenos Aires: Editorial Tiempo Contemporáneo.

Van Dijk, Teun. 1988. Texto y contexto. Madrid: Editorial Cátedra. 